\title{
Analysis of the brazilian federal bridge inventory
}

\section{Análise do inventário das pontes federais do Brasil}
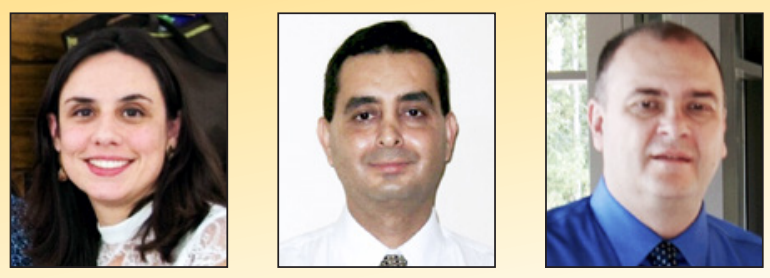

C. B. L. OLIVEIRA carolineburatto@yahoo.com.br http://orcid.org/0000-0002-8951-0511

M. GRECO a mgreco@dees.ufmg.br http://orcid.org/0000-0001-5500-0225

T. N. BITTENCOURT ${ }^{\mathrm{b}}$ tbitten@gmail.com http://orcid.org/0000-0001-6523-2687

\begin{abstract}
Bridge Management aims to provide an appropriate support to decision-making for maintenance, rehabilitation and repair strategies under constraint of limited budgets. In this regard, the Federal Brazilian Department of Transportation (DNIT) has developed the SGO - a Brazilian Bridge Management System (B-BMS) - and promoted the most comprehensive road bridge inventory under its direct administration. To improve the management of these bridge assets, the DNIT is working to develop a statistical model to predict the future condition of bridge: the most efficient and effective tool in a BMS to planning when the maintenance actions will be required. The current paper reports on findings of inventory, predominantly composed of reinforced concrete bridges, focusing on potential deterioration agents reported and checking their influence on deterioration conditions. Based on national database, the paper proposes a methodology to forecast Brazilian bridges deterioration rates. An example of application is demonstrated and satisfactory prediction accuracy obtained, even for few inspection cycles and under restricted database information.
\end{abstract}

Keywords: bridge management systems, bridge inventory, bridge deterioration models, Markov chains.

\section{Resumo}

A gestão de pontes promove suporte na tomada de decisões gerenciais, otimizando as intervenções necessárias sob limitações orçamentárias. Nessa perspectiva, o Departamento Federal de Transportes (DNIT) desenvolveu o Sistema Brasileiro de Gerenciamento de Pontes (SGO) e promoveu o mais abrangente inventário de pontes rodoviárias sob sua administração direta. Atualmente, o DNIT promove pesquisa para o desenvolvimento de um modelo estatístico de previsão das futuras condições das pontes: ferramenta basilar e de importância crucial no gerenciamento. O presente artigo apresenta os resultados do inventário, predominantemente composto de pontes em concreto armado, focando no registro dos potenciais agentes de deterioração e da sua possível influência no estado de conservação dessas estruturas. Baseado nas características do inventário, o artigo propõe uma metodologia para a previsão das taxas de deterioração de pontes brasileiras com um exemplo da sua aplicação, obtendo boa previsão do estado futuro mesmo quando utilizada em parques de obras com poucos ciclos de inspeções e restritas informações do banco de dados.

Palavras-chave: sistemas de gestão de pontes, inventário de pontes, modelos de deterioração, cadeias de Markov. 


\section{Introduction}

Bridges play a crucial role in civil infrastructure by providing crossings at critical locations. They maintain network continuity, traversing natural and human-made features that otherwise would add significant travel time and cost [1]. Concrete bridge structures designed to maintain their service and function over extended periods. However, they are exposed to the environmental conditions and subjected to many deteriorative influences, such as traffic wear and tear, exposure to deteriorative agents such as sulfates, chloride ions, construction or design errors and inadequate maintenance programs [2]. Bridges are crucial elements of any transportation network due to their strategic location and dangerous consequences if they collapse or if their capacity is impaired. An effective bridge-management program is a prerequisite to a successful horizontal transportation system.

Nonetheless, managing thousands of highway bridges has become increasingly critical in the past few decades, which led to the development of tools that help government agencies. Bridge Management Systems (BMS) are being designed to enhance the management strategies of large bridge networks. The primary objective of a BMS is to assist a bridge manager in making optimal decisions regarding allocation of a budgets to the Maintenance, Rehabilitation, and Replacement (MR\&R) needs of individual bridges (project level) or a group of bridges (network level) based on their life cycle cost assessment [3]. The BMS enables to a systematic determination of present and future predicted needs, as well as to list and prioritize maintenance, rehabilitation, and replacement actions and also provide guidance in the practical use of specific funds with possible regards to safety and budgetary constraints.

The effectiveness of a BMS relies on quality and accuracy of information contained in bridge inventory and data obtained through field inspections [4]. The database and inventory allow bridge managers to be fully informed about the conditions of the bridges under their control, so that they can make well based decisions about future maintenance and repair activities. In addition to the database,
BMS usually have three more modules: deterioration models, cost models, and MR\&R decisions or optimization models.

The deterioration module basilar and required to develop plans for MR\&R actions. There are several methodologies to forecasting bridge deterioration; mainly Markov chains models, regressionbased models, dynamic response sensors and artificial intelligence. All existing methods depend on the inspection data and each application is derived from the specific data available from inspections. Hence, the adoption of the methodology and its applicability rely on the characteristics of the inspections carried out. All the aspects considered, to obtain more accurate outcomes of deterioration rates, the inventory must have its peculiarities well identified to set the most appropriate method.

\subsection{Background}

Different agencies manage bridges in Brazil at the federal, state and municipal governments (public sector) levels. The Federal Department of Transport Infrastructure (Departamento Nacional de Infraestrutura em Transportes - DNIT) currently supervises the design, construction, operation, maintenance, repair, rehabilitation, and replacement of more than 5,000 bridges across the federal road network. The average age of the bridges in Brazil has been increasing continuously since 1960, which means that the bridges are aging despite the limited maintenance budget, due to Brazil's bottleneck economic development in transportation infrastructures [5].

As funding to meet the growing needs for new infrastructure and Maintenance, Repair, and Rehabilitation (MR\&R) of infrastructure becomes more difficult to obtain and maximize the service life of bridges. Tools to assist in optimizing need-based scheduling of MR\&R activities, as well as tools to aid with decision-making strategies, are essential to the efforts of DNIT's Structures Department. To support performance-based and data-driven planning, a bridge management system denominated SGO (Sistema de Gestão de Obras-de-arte) stores bridge data, including bridge characteristics, inspection data, and rating information. To improve SGO, DNIT is

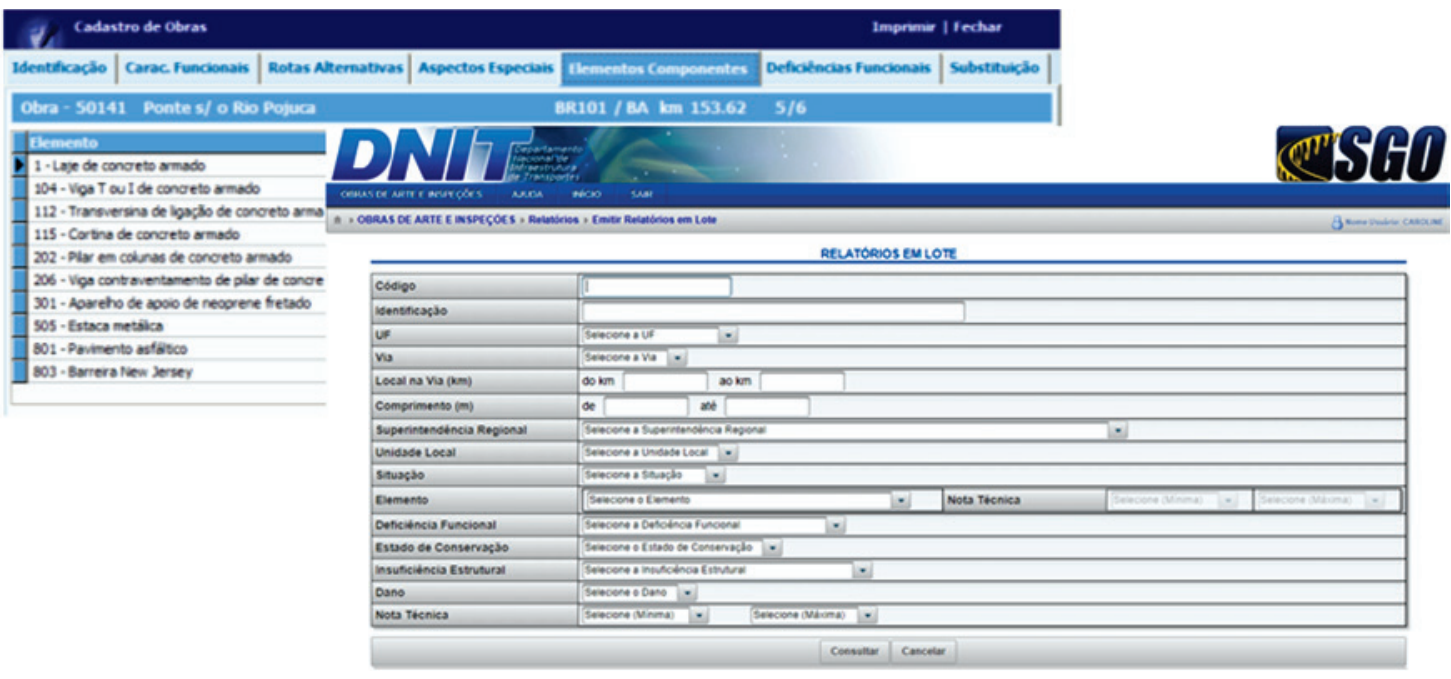

Figure 1

Data entry screen of SGO Mobile inspector version 
promoting research to develop deterioration and economic models to predict outcomes and to guide network-level and project-level decisions and optimal preservation policy.

After the latest implemented version of SGO, in 2004, the new software design has improved advanced computer tools for inspection data entry, prepared to gather inspection information, catalogue pictures and drawings of basic schemes as well as short videos. Mobile devices were able to register inspections through SGO Mobile and send the information directly to SGO Web [6]. Figure 1 show the data entry screen of SGO Mobile inspector version and the data query module of SGO Web.

Above all technological improvement, the most important advance has been the introduction to a bridge element-level approach. Bridges are presented in terms of their structural components, and recording their different types include beams, arches, decks and deck slabs; railings and traffic barriers, bearings, deck joints, piers and columns, abutments, approach slabs, among others. The characteristics for each element are assigned, as their geometrical form, material and structural function. The latest inventory was finished in 2017. It was the most comprehensive national inventory, with 4,732 structures performed at element-level inspection, including almost $80 \%$ of total road bridge infrastructure.

\subsection{Objectives}

DNIT inventory data was organized in a logical outline to give a complete overview of inventory contents. The primary focus is to identify required information, which will improve research methods to forecast Brazilian bridges deterioration, so as to enhance SGO. Therefore, possible deterioration agents and damages, its types, frequency and location should be singled out.

Generally supporting significant MR\&R strategies, BMS is based on a reliable bridge deterioration model [7]. Similarly to BMS, the deterioration model accuracy depends mainly on registering as much pertinent information on the bridge as possible. The singularities of the national inventory it is also essential to develop a methodology to forecast Brazilian bridges deterioration. These findings will determine the most appropriated method, considering a minimum required accuracy, best suited to national practices of inspection of concrete bridges and, mainly, adjusted to available data characteristics in SGO. The lack of available information about bridges degradation rates in Brazil prevents managers from being able to predict when these structures will need maintenance services. Therefore, it considerably affects strategic planning and schedule of MR\&R actions.

Notably, DNIT Transport Programs and Projects costs need to be predicted one year in advance, so that the Brazilian Speaker of the House of Representatives requests the funds. If DNIT does not have any predictive tool to foresee the future of the bridge conditions, the programmed cost may vary from the real cost needed to carry out the MR\&R required actions. In addition, private companies would also be able to plan their required actions and associated costs.

\section{Condition index}

Regarding risk identification, required maintenance, strengthen- ing and replacement of components, bridge assessment data is a crucial input to decision-making. This information together with engineering judgment composes the basis for the development of work programs. Infrastructure maintenance and rehabilitation decision making are based on current and future facility conditions [8]. To this end, inspections are conducted to document noticeable changes from a new-condition. It is a widespread practice to qualitatively evaluate the condition of a bridge and its elements using an ordinal scale. The condition of each element is reported according to a condition state (technical evaluation in SGO) or "Index of Condition" (IC), which is a quantitative measure of deterioration, safety and serviceability. The IC is determined based on the specific degradation or defects apparent at the time of inspection.

The IC can be assigned by element, by set of bridge elements or by general structures and reflects the final result of the inspection. Usually, the IC adds a subjective attribute of the structural condition of the bridge, linked with bridge safety. The Brazilian standards DNIT 010/2004 [9] and NBR-9452/2016 [10] adopted five discrete levels of rating, 1 to 5 , from the worst to best state. Frequently, $\mathrm{IC}=1$ and $\mathrm{IC}=2$ are referred to as reaching or having reached an intervention point, which acts as a trigger to perform an action. These IC typically represent the need for measures to be taken soon or immediately. Also, IC=1 could denote reduced structural capacity or serviceability.

Before the SGO latest version, the inspection data evaluated the listed materials, the physical condition of the deck, superstructure, substructure and infrastructure of bridge, including elements. As a result there were five IC, one general and four specific attributes for major regions. The SGO's third version made it possible to assign condition ratings to each bridge element. It also permitted to certify whether or not the component has structural function.

\section{Bridge deterioration models}

There are several approaches to forecast bridge deterioration. The models of bridge deterioration are categorized in empirical or mechanistic methods. The empirical models are based on experimental data, while the mechanistic models are developed from analytical models associated to degradation mechanisms. Despite the different techniques, these methods could be classified in deterministic, stochastic and artificial intelligence models [11].

The deterministic models of deterioration are the most straightforward approach to predict future condition of bridges. They are obtained through the use of straight or curved lines, and a regression process sets their shapes and parameters. Stochastic models measure the bridge deterioration process as one or more random variables and attributed occurrence probabilities of a specific state within a sample. The third method, artificial intelligence models, exploits computer techniques that aim to automate intelligent behaviors [12]

\section{Markov chain method}

Stochastic deterioration models aim to associate time with degradation process based on one or more random variables. To researches in the field of bridge deterioration, Markov process is discrete in time and in variables, especially due to the discrete 
nature of IC observed in inspections. Thus, Markov chains, a particular case of the Markov Process, are suitable and widely used to develop statistical models of deterioration of various types of infrastructure materials, such as pavements, bridges, buildings, among others. In state-based models, the deterioration process is modeled through as a transition from the current state $i$ at an initial time to a state $j$ at time given by:

$P_{(\Delta t) i j}=P_{r}\left(X_{\Delta t}=j X_{\Delta t}=i\right)$

The process is independent of type: for any given condition state, a fixed probability exists for its transition into another condition state. The probabilities of a bridge change IC are represented by a matrix $(n \times n)$, where $n$ is each IC levels, denominated Transition Probability Matrix (TPM):

$P=\left[p_{i j}\right]=\left[\begin{array}{cccc}p_{11} & p_{12} & \ldots & p_{1 n} \\ p_{21} & p_{22} & \ldots & p_{2 n} \\ \vdots & \vdots & \ddots & \vdots \\ p_{m 1} & p_{m 2} & \ldots & p_{m n}\end{array}\right]$

Markov Chains is applied in cases of bridge deterioration based on cumulative and probabilistic damage approach, in which the IC decreases, after several transition periods, is expected [13].

\section{Brazilian bridges characteristics}

The recent Brazilian bridge inventory registered 4,725 bridges. It represents more than $80 \%$ of the number estimated by various jurisdictions of federal government. $65.53 \mathrm{~km}$ of bridge extension were registered by the inventory. The vast majority of the federal highways located in Rio de Janeiro and São Paulo are directly administrated by these states. For this reason they were not inspected in this inventory conducted by the DNIT. The majority of the bridges inspected in the DNIT inventory are reinforced concrete (RC) bridges (99.2\%). The most used system, more than $58 \%$ is reinforced concrete beam (2,764 bridges), followed by reinforced concrete slab, 777 bridges and the post-tensioned system, 622 bridges. This results in the need of more management attention

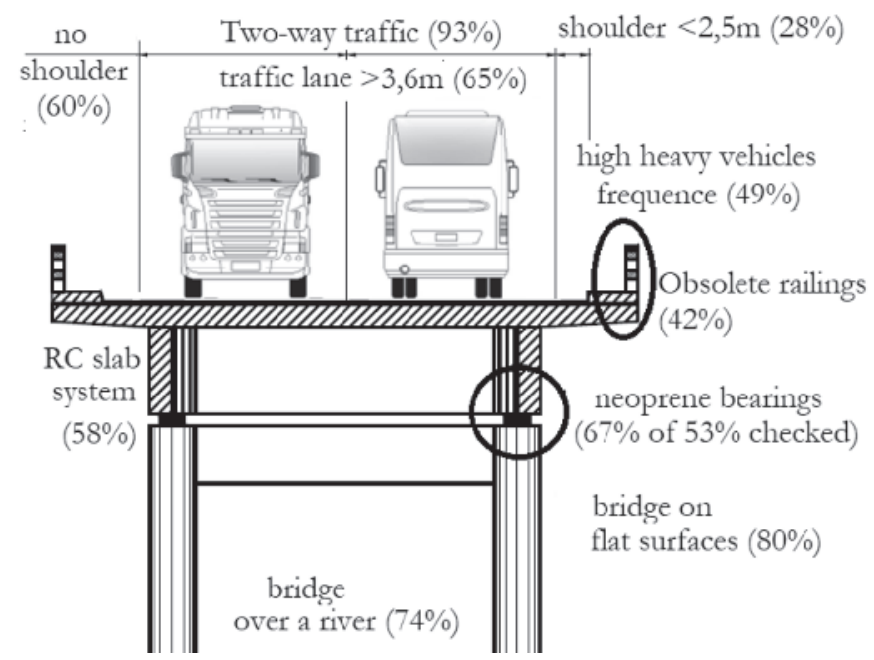

Figure 2

Typical cross-section of Brazilian bridges considering that $\mathrm{RC}$ bridges face problems due to fatigue caused by repeated loading which can lead to progressive deterioration of bond and may cause premature failure. Furthermore, corrosion of steel bars can lead to substantial reduction of loading cycles and bond failure.

Due to slip growth, repeated loading leads to the increase of crack width and deflection, which under aggressive environment conditions strongly affect durability of RC structures. For high corrosion level, if the longitudinal bars and the contact stirrups were severely damaged or even ruptured, brittle failure may occur at a very low load. This is quite dangerous in the case of safety-related structures [14].

Most Brazilian federal highways structures were built over rivers, totalizing 3,789 bridges $(74 \%)$. There were 752 overpasses through roads and 153 through railways. These bridges show evidences of the characteristics of Brazilian infrastructure: predominance of highway traffic as compared to rail traffic and presence of most of the highways in rural areas of relatively low population density [15]. Although the available bridges designs were exhaustively investigated, only $22 \%$ (1,032 bridges) had their age recorded. For the sake of practicality, the bridges were into periods by existing standards, as determined in The Manual of Road Bridges of the National Road Research Institute (IPR) [16]. Almost 25,7\% (265 bridges) of the total of 1,032 bridges whose age was recorded were constructed before 1960. Most of them (about 531 bridges, $52 \%$ of the total) were built between 1960 and 1975 . According to The Manual of Road Bridges, these structures followed Brazilian Standards number 1, 2 and 6/1960, with a loading capacity of up to $36 \mathrm{~T}$ (tons per axle), 10 meters total deck width , and 0.90 meters high obsolete railings.

There were 2,025 registers of bridge live load capacity, $74 \%$ of which being overloaded, 256 design loading bridges of up to $24 \mathrm{kN}$ (axle load), and 1,260 of up to $36 \mathrm{kN}$. Functionally obsolete due to inadequate design, ever-increasing and changing traffic, and absence of needed strengthening interventions, are common challenges faced by governments, even in developed countries [17]. Most of the bridges ( $80 \%$ of 4,725 bridges) are over flat surfaces, and more than $93 \%$ are two-way traffic bridges, $65 \%$ of the lanes being equal to or wider than 3.6 meters. However, there are 1,419 $(35 \%)$ bridges whose lane widths are insufficient - less than 3.6 meters per lane in double lane roads.

Access equipment was not used in the inspections. For this reason, 2,229 bridges (47\%) did neither have their bearings checked, neither had their type registered nor their function and damage states registered. The most commonly observed functionality deficiency was obsolete railings, registered in 2,095 bridges. The research also registered 2,849 bridges with no shoulders and 3,271 bridges less than 2.5 meters shoulders. Figure 2 gives an overall idea of the typical cross-section of Brazilian bridges.

Drainage was insufficient in 681 bridges. High levels of heavy vehicle traffic were observed in 2,923 (49\%) of the bridges, a fact which is likely to affect the deterioration rates of the structural elements. These results provide evidence to the facts that weight vehicle control and planed regular inspections are fundamental factors to preserve bridge structural integrity. The comparison between the static effects of the actual traffic of heavy vehicles and those generated by the live load model given in the current national 
code NBR 7188/2013[18] raises another concern. The simulation showed that Brazilian code load models may not adequately reproduce the real traffic of heavy vehicles and may, in many cases, be non-conservative [19].

\section{Brazilian bridges inspection results}

Inspections were conducted according to the Brazilian Standards NBR-9542/2016 (2016 version) [9] and DNIT010/2004-PRO [10] The worst general $I C=1$, suggesting immediate intervention, was found in only 8 bridges. Besides, 196 bridges were classified in $\mathrm{IC}=2$, demanding mid-term interventions, resulting in $4.2 \%$ of total bridges inspected requiring MR\&R scheduled actions. Approximately $38 \%$ of inspected structures were evaluated as $I C=3$ ( 1,803 bridges), having minor structural damages, and need of maintenance and regular inspections only, not requiring emergency action.

Finally, 1,987 bridges were evaluated $\mathrm{IC}=4$ and $756 \mathrm{IC}=5$,

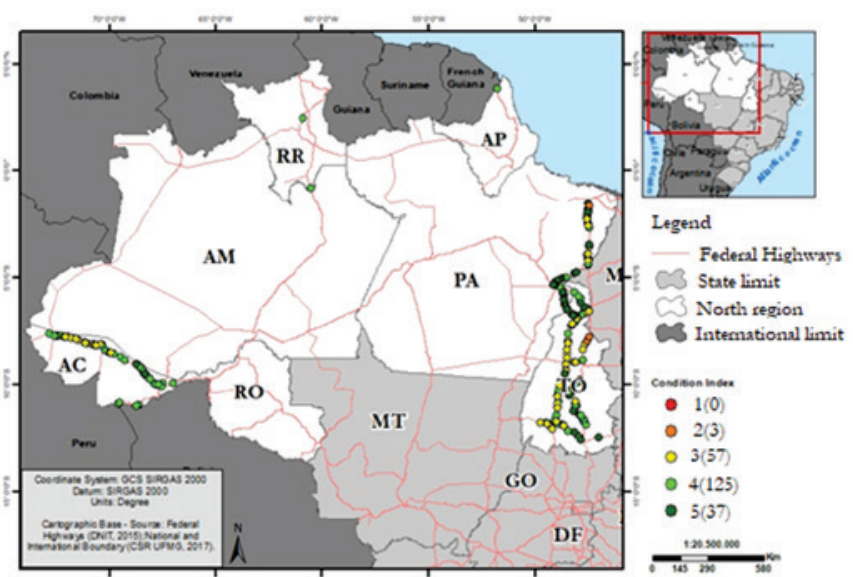

\section{Figure 3}

Geographic distribution of bridges inventory and $\mathrm{IC}$ registered in North region

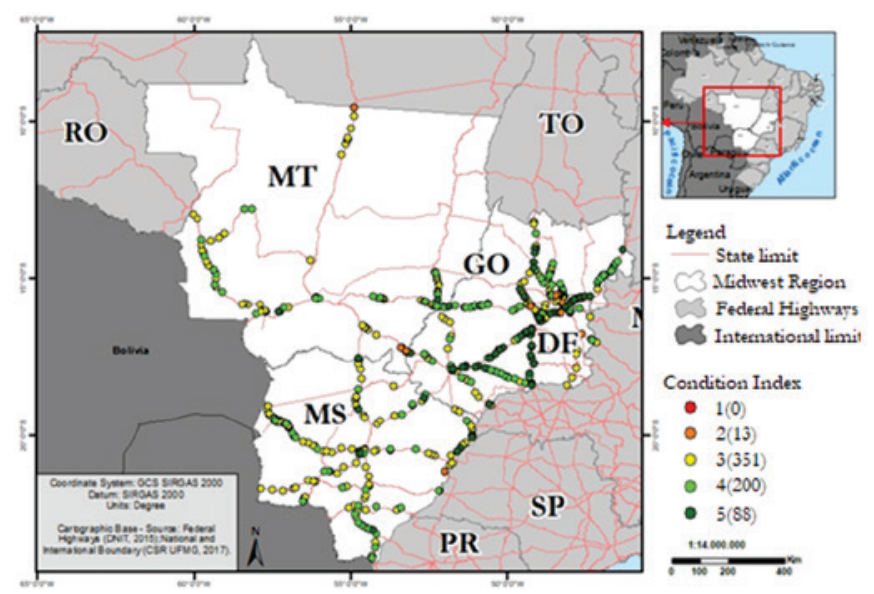

\section{Figure 4}

Geographic distribution of bridges inventory and $\mathrm{IC}$ registered in Midwest region

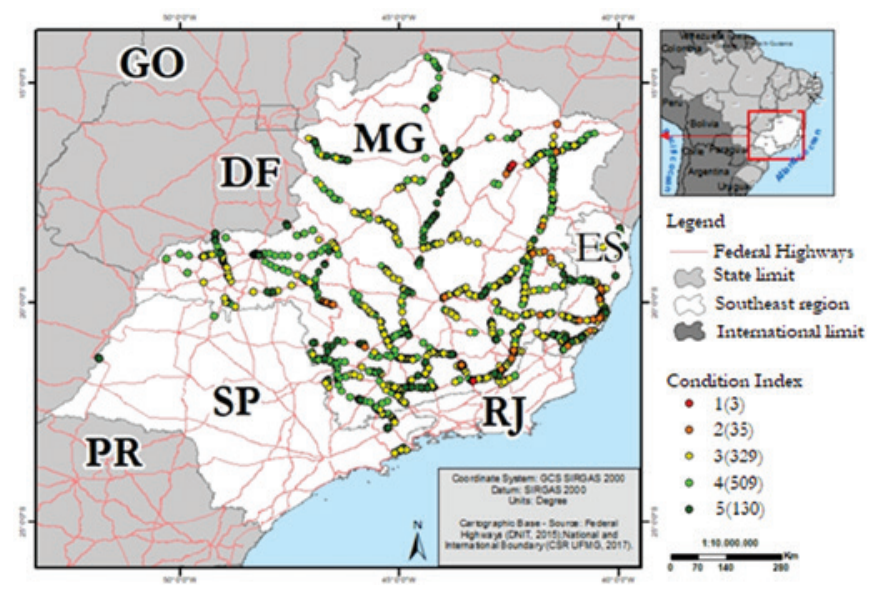

Figure 5

Geographic distribution of bridges inventory and IC registered in Southeast region

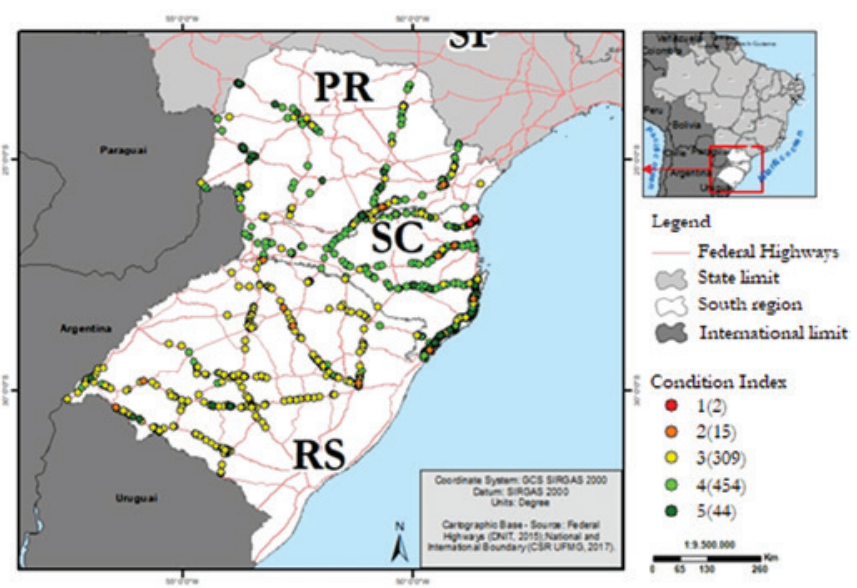

Figure 6

Geographic distribution of bridges inventory and IC registered in South region

totalizing $58 \%$ of the total with no structural damages, demanding only maintenance and regular inspection. These records suggest a positive scenario for the conservation conditions of Brazilian structures, considering their 40 year-old age average, their exposure to aggressive agents and the absence of a maintenance program before the inventory.

The SGO recorded information of geographic coordinates of each bridge during the inventory. This information was exported to a free geographic information system application. For the analysis of the data, the IC of each bridge was assigned in according to the results of the inspection. The Brazilian federal roadmap was used, and the bridge coordinates were corrected. Figures 3 to 7 show the distribution of bridges and their condition, considering Brazilian geographic and statistical regions.

Ever since the time of the inspection, DNIT has made several bridge interventions according to the observed condition and the average traffic analysis. However, it is essential to understand the 


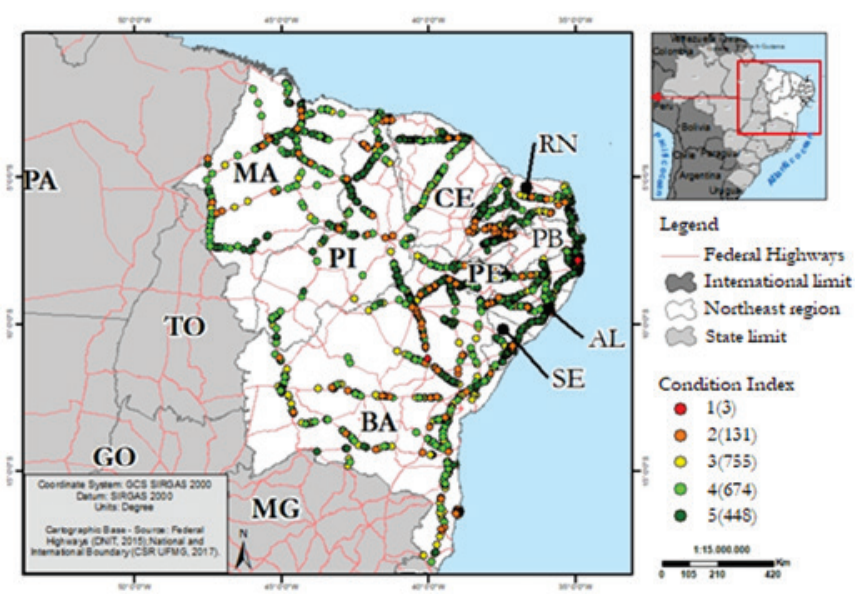

Figure 7

Geographic distribution of bridges inventory and IC registered in Northeast region

deterioration mechanisms of structural materials and components to develop more accurate maintenance and replacement programs to prevent continuous deterioration and to ensure optimal budget spending.

\subsection{Damages incidence}

Most of the numerous damages identified on inspections are shown in Table 1 and represent $75 \%$ of 20,389 defect registers. They were evaluated according to their severity degree, and for each incidence, an IC was marked. It is important to emphasize the importance of damage measure per element in addition to regular inspections. Regular inspections at element-level provide significant data which enable researches to develop a deterioration model of Brazilian bridges, crucial knowledge to life cycle analysis leading to optimal bridge management.

Most of the prevailing damages were associated with reinforcement corrosion and concrete degradation, corresponding to $66 \%$ of total registered defects, followed by expansion joints damages with $9.4 \%$. Reinforcement corrosion constitutes the major factor of RC structures degradation. It results from the change of steel mechanical properties, longitudinal cracking of concrete cover, change of bond strength between steel and concrete, loss of serviceability and eventually loss of safety
[20]. For instance, the mechanical behavior intended during the design phase may not be observed during the structural life, indeed, and it can change drastically when corrosion effects are accounted [21]. Therefore, its high occurrence requires more detailed MR\&R actions plan focused on increasing the durability of these structures and to ensure safety.

Figure 8 show the damages by structural elements. Concrete deck was the structural that showed more damage incidence, corresponding to 4,983 of the registered occurrences (31\%). Due mainly to the effects of direct exposure to traffic loads and environmental degradation factors, numeral types of research focus on the deck system, thus considered the weakest system of highway bridges [2]. In the same way, the rate at which bridge decks deteriorates is an important element used to estimate MR\&R costs. Efflorescence and leaching of concrete was the most observed deck defect $(38 \%)$, followed by water leakage trough concrete cracks $(31 \%)$, spalled concrete and exposed steel rebars $(20 \%)$ and corroded steel rebars $(6 \%)$.

The second structural element with high damage occurrence (2,376 times) was longitudinal girders. They are directly connected to the deck to transmit efforts to mesostructure. Spalled concrete and exposed steel rebars totalizing $31 \%$, efflorescence and leaching of concrete, $29 \%$ and $16 \%$ spalled concrete and steel rebars exposed and already corroded of total longitudinal girders damage registered. Retaining wall was the third element $(1,804$ occurrences) with $39 \%$ of water leakage through concrete cracks, $32 \%$ efflorescence and leaching of concrete damage.

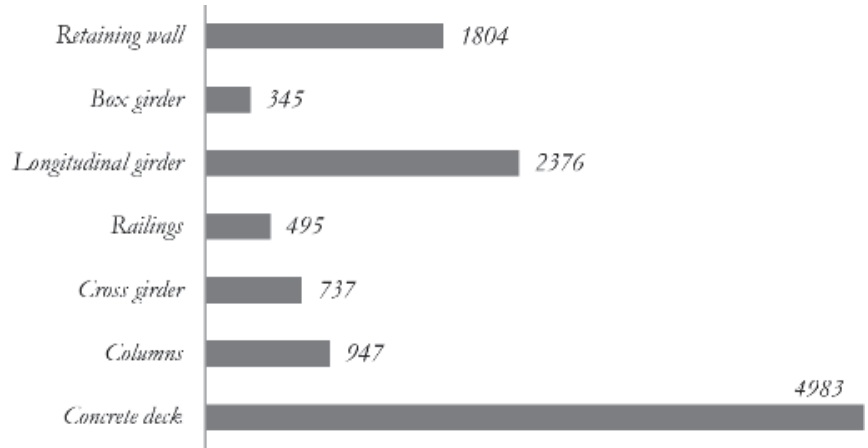

Figure 8

Damage frequency by structural RC element of DNIT bridges inventory

\section{Table 1}

Frequence and IC of major damages registered in DNIT bridges inventory

\begin{tabular}{cccccc} 
& & & IC & \\
\cline { 2 - 5 } Damage & $\mathbf{1}$ & $\mathbf{2}$ & $\mathbf{3}$ & $\mathbf{4}$ & $\mathbf{5}$ \\
\hline Efflorescence and leaching of concrete & 5 & 146 & 1,798 & 2,480 & 21 \\
Damage in expansion joints & 1 & 187 & 514 & 1,206 & 12 \\
Spalled concrete and exposed steel rebars & 6 & 177 & 1,613 & 1,730 & 19 \\
Spalled concrete and exposed and corroded steel rebars & 4 & 140 & 745 & 860 & 10 \\
Water leakage through concrete cracks & 4 & 103 & 1,371 & 1,346 & 6 \\
Steel rebars without cover protection & 2 & 54 & 277 & 534 & 5 \\
\hline
\end{tabular}




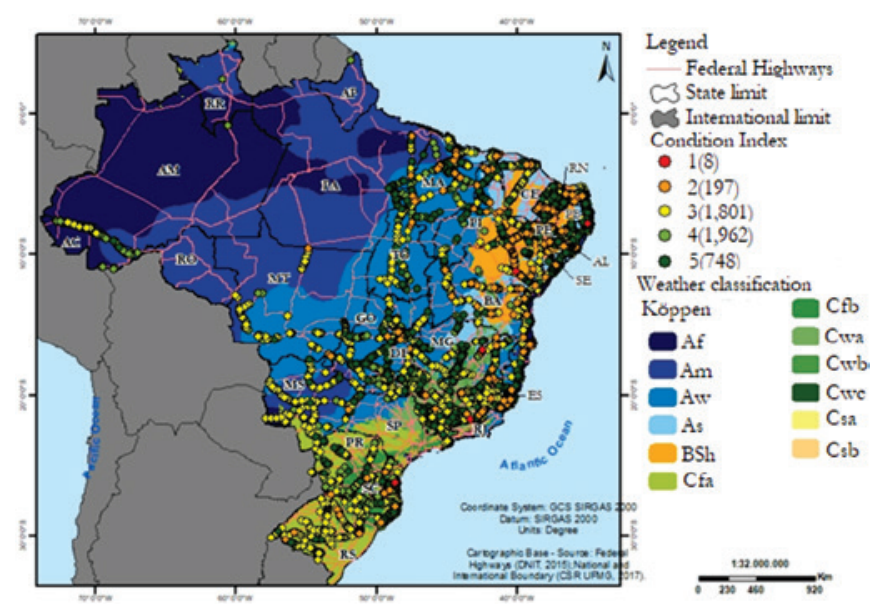

Figure 9

Köppen-Geiger climate classification and IC distribution

\section{Reported deterioration agents effects on IC value analysis}

Deterioration of bridge elements depend on several parameters related to bridge design, construction, geographical location and environment, and traffic volume. Therefore, it is important to classify bridges based on the values of these parameters, so that homogenous and consistent data can be used to develop deterioration models with required accuracy. For this reason, filtered data records are classified based on the following parameters.

\subsection{Climate}

To investigate a probable relationship between climate characteristics and current IC, the geographic coordinates of bridges were processed by a geoprocessing system on a Köppen-Geiger climate classification. Figure 9 shows compiled information. Indeed, climatic bridge location is not the exclusive and conclusive deteriorative agent to influence IC. As a result, it is possible to have contrasted IC values in the same climatic classification. However, it is possible to verify that some climatic regions have the largest number of bridges with $I C=1$ and $I C=2$ than others. To better analyze that relationship, these bridges are shown apart in Figure 10.

The bridges showing the worst IC concentrate mostly in the Northeast region. Of the 2,011 inspected bridges in this region, $6.5 \%$ were classified as $I C=2$. It is also possible to verify some road segments with a sequence of bridges with $I C=1$ and $I C=2$. These bridges were located mainly in the Northeast region with BSh Köppen-Geiger characteristics. The Bsh classification stands for a semi-arid climate, with low annual precipitation index only in the winter season below potential evapotranspiration, resulting in very dry and hot atmospheric conditions.

In the Southeast region, 35 inspected bridges were evaluated as IC $=2$, representing $3.5 \%$ of the 1,006 total bridges inspected in Minas Gerais and Espírito Santo states. It is possible to verify that $\mathrm{IC}=1$ and $\mathrm{IC}=2$ scores had meaningful incidence in Aw Köppen-Geiger region climate and bordering regions. The Aw classification shows a tropical environment, often composed of two basics seasons: winter and summer. However, a winter season is less prominent or even inexistent. The temperatures remain relatively hot throughout the year, and there is a heavy annual precipitation concentrated only in summer season, resulting in dry winter season.

The Southern region has the lowest IC incidence, having only 15 IC $=2$ bridges out of 824 . It represents only $1.8 \%$ of the total number of bridges in the region. The location of these bridges does not seem to follow a pattern, but they are mostly related to the Cfa climate classification. This type of climate is classified as humid subtropical climate, with hot and humid summers and mild winters. There are precipitations all over the year.

The results of the inspection show that the bridges in the poorest condition are located mainly in a hot and dry climate. As regions register an incidence of higher precipitation and low temperatures, the condition of concrete bridges is better, and the number of bridges in poor condition decreases. The bridges in the Southern region follow this course. The Cfa climate is alongside the Cfb classification is alongside the Cfa climate in Southern Region and the main difference between these classifications is the variation in summer temperatures. The $\mathrm{Cfb}$ climate region has higher temperatures than Cfa region. This influence has already been evaluated by renowned researches and some Brazilian ones as well, such as research conducted by LENCIONI [22]. This conclusion leads to further investigation on the deterioration rates per climatic region, where different deterioration indexes are expected.

\subsection{Bridge age}

At the inventory shows, only 1,032 bridges are registered with their corresponding age in SGO. This is probably due to the non-existence of the necessary records of the original designs and successive MR\&R actions. Nonetheless, this age register has crucial importance and is the most frequently used database to present the deterioration rates and to predict the future condition of bridge assets.

For the group of bridges having their age listed in the inventory, the IC probably decreases when bridge age increases. However,

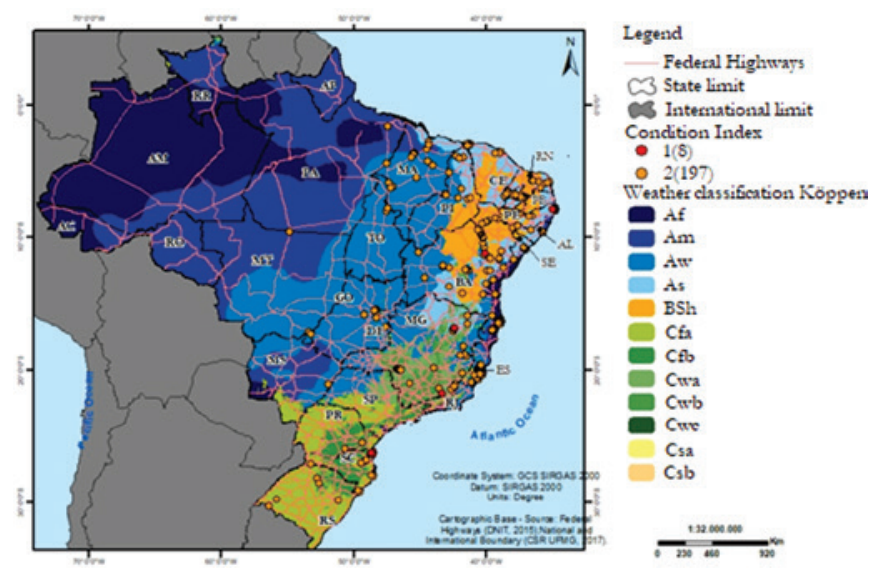

Figure 10

Köppen-Geiger climate classification and $\mathrm{IC}=1$ and $\mathrm{IC}=2$ distribution 


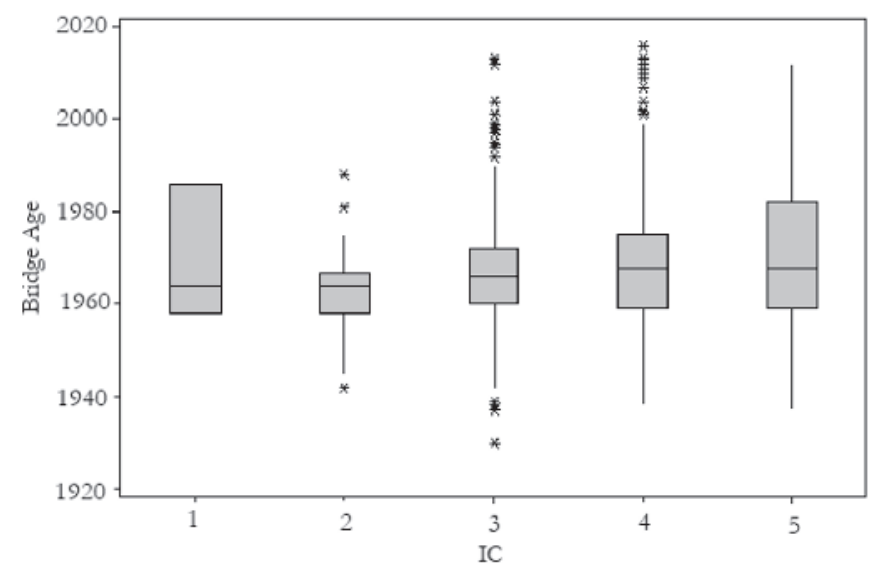

Figure 11

IC versus Bridge Age

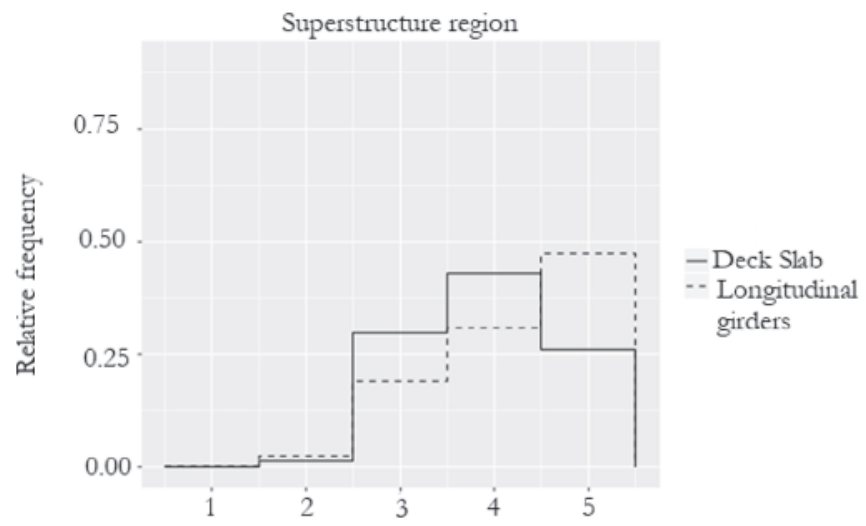

Figure 12

IC distribution of Deck Slab and Longitudinal girders

Figure 11 shows that there is no apparent relationship between these variables. Spearman's correlation coefficient between the variables "Bridge age" and "IC" was 0.13 ( $p$-value $=0.000)$, suggesting that these variables present very low or non-existent correlation for practical purposes. Spearman's correlation evaluates the monotonic relationship between two continuous, discrete, or ordinal variables. It is a non-parametric method that uses only the stations and makes no assumptions about the distribution of the data. Correlation values of -1 or 1 imply an exact linear relationship. The zero indicates absence of a monotonic relation [23].

MOSCOSO [24] conducted research that proposed deterioration models for Brazilian bridges, using estimate deterioration rates of Nevada bridge assets. To apply these rates to Brazilian bridges, MOSCOSO analyzed registered ages and found bridges with IC = 5 , regardless the old age of them had. According to MOSCOSO, this finding possibly has its cause possibly in not registered MR\&R actions along this period.

To determine deterioration rates, the age input of a given bridge is usually changed if maintenance actions resulted in significant IC changes. For example, if a singular bridge has changed its condition state from IC $=2$ to $I C=5$ after MR\&R action, it is possible to infer that its previous conditions in the past have significantly changed. Its future durability conditions will also be substantially affected. In this case, the bridge age variable must be adjusted in order to measure deterioration taxes. In contrast, if the bridge age is not adequate to deterioration measurement rates, it will lead to a significant deviation of IC bridge predictions, with a misleading future condition state output [25]. Seen from this perspective, for deterioration rates the bridge age strongly depends on performed interventions over the years. Such interventions must be registered on BMS with characterized MR\&R action. Considering the limited database in SGO and the absence of MR\&R actions records, investigations on Brazilian bridge deterioration rates based on bridge age and starting from the current IC can lead to unreliable results.

\subsection{Element type}

The deterioration process shows the complex phenomena of physical and chemical changes occurring in different bridge

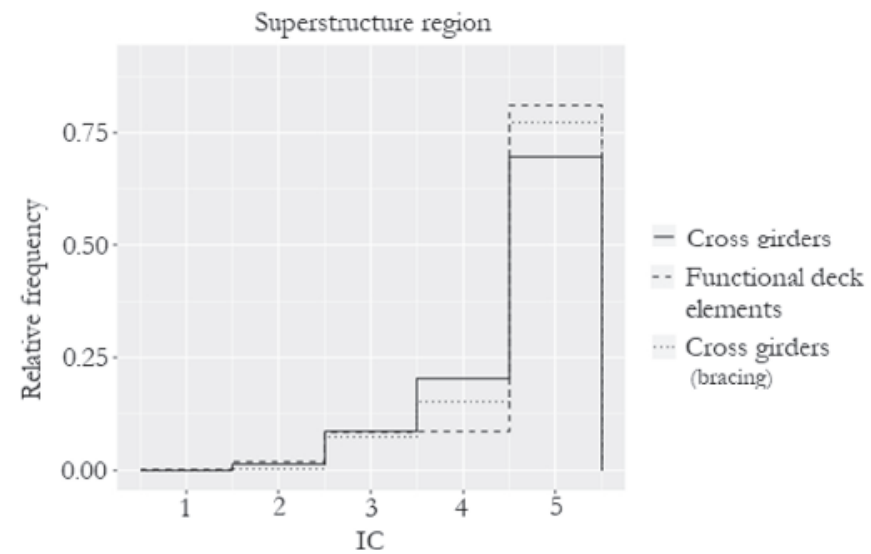

Figure 13

IC distribution of cross girders and functional deck elements

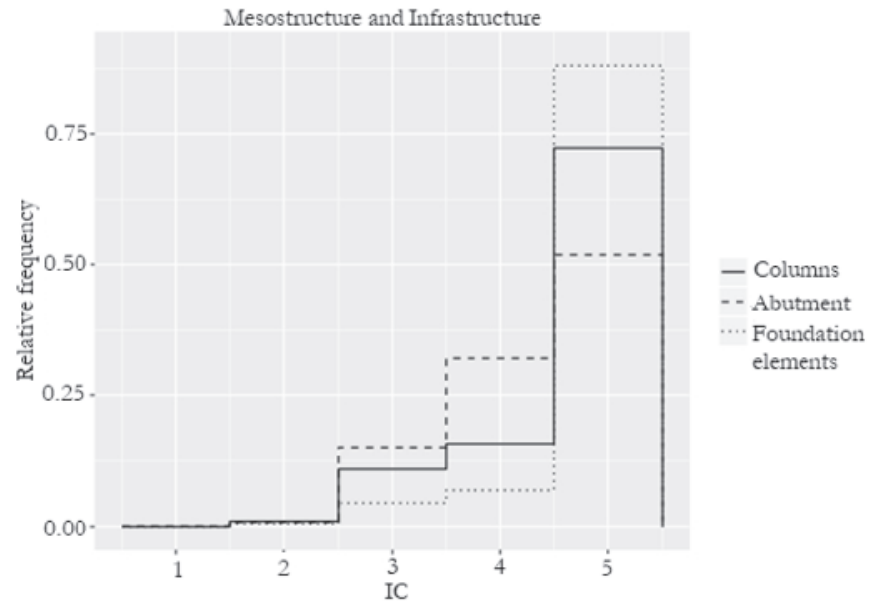

Figure 14

IC distribution of columns, abutment and foundation elements 
components. What makes the problem more complex is the fact that each element has its own deterioration rate [26]. To achieve probable differences registered in DNIT inventory, the IC frequency for the three main bridge components, superstructure, mesostructure and infrastructure, was analyzed and is showed in Figures 12 to 14 . The results presented the highest amount of characterization in low ICs associated to bridge deck. The low IC incidence tends to decrease as the structural element as more distant from the region receiving direct impact of vehicles. Such results confirm recognized scientific studies and suggest particular deterioration rates to each bridge component.

\subsection{Other possible deterioration influences}

Traffic load design is another possible deterioration agent in road bridges. DNIT inventory reported related to 2,023 bridges inspected according to NBR 7188/2003 [18]. Figure 15 shows a moderate bias to better condition states assigned to designed T45 truckload bridges. This result could be justified by newer bridges or rehabilitation actions on old ones. Besides, bridges design to modern standards and with improved durability characteristics may perform much better than older bridges, in the same operational environment [27]. Therefore, deterioration rate studies can lead distinct results according to bridges load truck design.

In addition to this analysis, a high incidence of heavy traffic wheel loads was reported for 2,149 bridges ( $45 \%$ of total inspected). Due to these Brazilian highways traffic characteristics, the T45 bridges could be more adjusted to current operational loads. The bridges characterized with heavy wheel load presence follows the IC global distribution: $4.9 \%$ with $\mathrm{IC}=2,39.6 \%$ with $\mathrm{IC}=3,36.7 \%$ with $\mathrm{IC}=4$ and $18.8 \%$ with $\mathrm{IC}=5$. In fact, to provide a more effective analysis, the data of traffic volume and vehicles characteristics should be recorded in data inventory for each bridge.

The analysis of impact of aggressive environment conditions is difficult to perform in view of the scarce number of bridges with this data recorded, only to 69 bridges. In addition, these bridges showed the same IC global distribution. For a better prediction accuracy, future inspections must contain information on traffic characteristics, volume, as well as more detailed aggressive environmental aggressive conditions.

\section{Assumptions}

In general, stochastic simulations based on bridge age can hardly be processed. Despite the availability of bridge age, insufficient registers of MR\&R actions could lead to unsuitable parameters. To predict future IC, artificial intelligence methods can hardly be performed based on available SGO information. These methods rely on more comprehensive data information to link the current performance with the characteristics of the bridge and the external factors to which it is submitted. A bridge having poor durability characteristics may deteriorate much more rapidly than one with good durability characteristics. These data description are not included in the SGO.

The polynomial regression analysis requires sufficient bridge inspections cycles with IC decreases. Bridge condition does not usually change significantly during short-term periods, and it reflects in a very reduced database to established reliable parameters to determinate models [7]. Moreover, Brazilian IC scale has only 5 levels, resulting in a higher probability of bridge remaining in the same condition state or IC, even after MR\&R actions or under some deterioration occurrences.

Widely used in BMS, statistical models based on Markov method have merely computational implementation with relative accurate outputs. Despite the fact that DNIT database started the register of bridge inspections only in 2013, after 4 (four) or more inspection future cycles, it will be possible to forecast probable future IC with enough accuracy to provide a more realistic federal budget. Transition Probabilistic Matrices (TPM) for each deterioration influent agent related in item 7 can be elaborated to estimate specific deterioration rates using the same method.

Deterioration models methods frequently use bridge age to assign data future state prediction. However, DNIT data sets do not have this information, and achieving complete data can present a significant challenge. Despite these usual practices, state-based models as Markov methods, and specifically Markov chains, could result in important management results to short-term predictions analysis, while the information is not complete gathered. For the suggested methodology, time interval will be computed from the first inspection with related IC. As a result, when deterioration curves start from the current bridge current state (IC), it may assume initial values different from 5 . The method will not indicate a complete model for bridge deterioration, but it is able to show the deterioration rates for short periods of time. The estimated annual bridge MR\&R cost estimates of the Federal budget will also have a real-based index for its most accurate evaluation. Above all, this approach could be already implemented in SGO to achieve acceptable results after few inspection cycles. After having the routine implemented, SGO can improve its use up to a more efficient bridge management system.

\section{Benchmark example}

As benchmark example, a bridge network is selected to demonstrate the advantages of the proposal approach. The information of bridge network is from Brazilian Road BR-381, knowing as "Rodovia Fernão Dias", obtained from the Brazilian Agency of Land

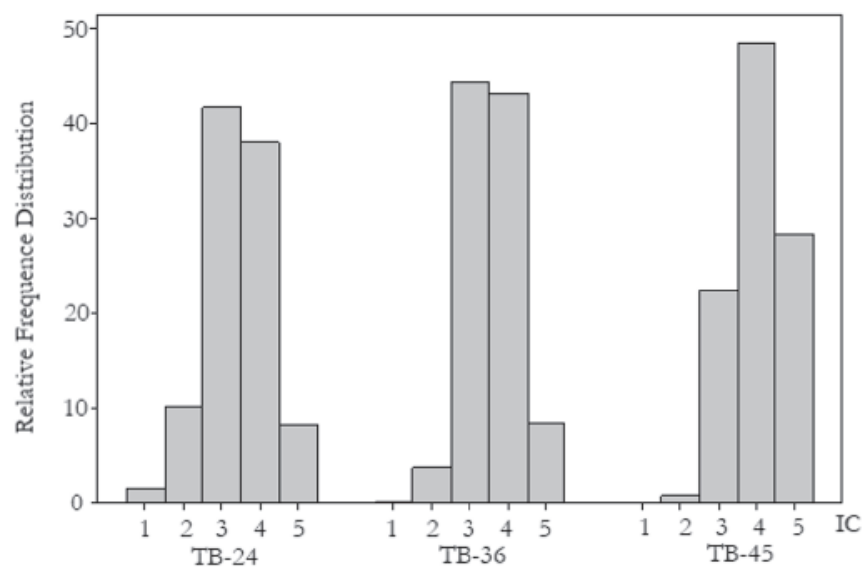

Figure 15

IC distribution versus truck-load design bridge 
Table 2

IC bridges distribution of Fernão Dias road dataset

\begin{tabular}{cccccc}
\hline Year & IC=5 & IC=4 & IC=3 & IC=2 & IC=1 \\
\hline 2008 & $2(1 \%)$ & $268(91 \%)$ & $16(5 \%)$ & $7(2 \%)$ & 0 \\
2009 & $3(1 \%)$ & $216(73 \%)$ & $68(23 \%)$ & $6(2 \%)$ & 0 \\
2010 & 0 & $221(75 \%)$ & $68(23 \%)$ & $4(1 \%)$ & 0 \\
2011 & 0 & $220(75 \%)$ & $70(24 \%)$ & $3(1 \%)$ & 0 \\
2013 & $10(3 \%)$ & $245(84 \%)$ & $36(12 \%)$ & $2(1 \%)$ & 0 \\
2014 & $13(4 \%)$ & $240(82 \%)$ & $39(13 \%)$ & $1(1 \%)$ & 0 \\
2015 & $13(4 \%)$ & $240(82 \%)$ & $39(13 \%)$ & $1(1 \%)$ & 0 \\
\hline
\end{tabular}

Transport (ANTT). Bridge inspections were carried out from 2008 to 2015 , resulting in 7 cycles, with annual inspections, according to the Brazilian standards NBR-6123 (old version - 2013) and DNIT $010 / 2004$, as well as DNIT inventory. The main bridge regions as superstructure, mesostructure and infrastructure were evaluated with respective IC. The ANTT data was available only in non-editable files reports, and a computational routine was implemented to organize data to enable stochastic simulation.

To select data more representative of the deterioration process, a filtered data was implemented according to AGRAWAL \& KAWAGUCHI [28]. Inspections reports with missing or incomplete data were removed. For example, IC during periods between two inspections should be the same as the IC at the previous inspection for bridges without MR\&R actions. To better understand rates, all data cycle with IC improvement rejected. Bridge data with unusual IC drops were disregarded because natural deterioration process decreases gradually over time. However, a sudden drop in IC over two consecutive inspections may be caused by occasional situations, for example, natural disasters, traffic accidents, etc. These occurrences do not reflect normal operational deterioration, peculiar to the database showing a one-year inspection interval. Every increased IC to a higher level was not included; this can be considered as a consequence of MR\&R actions.

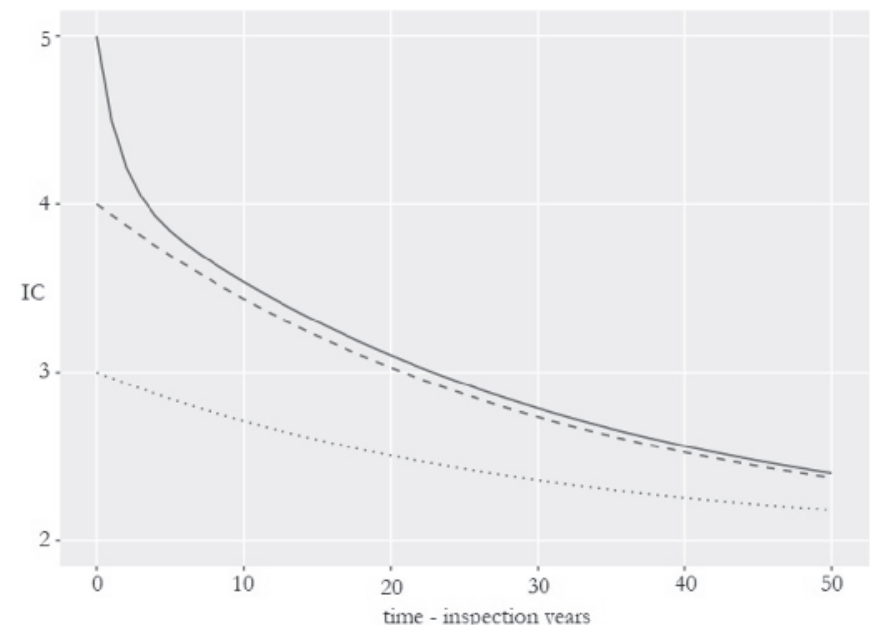

Figure 16

Deterioration model of Fernão Dias Road bridges General IC
The Markov chain use was possible because inspections were performed annually, resulting in the discrete time necessary to apply the method, according to ANTT Road Exploration Program (PER). Unusually, the inspection cycle from year 2012 to 2013 has 17 months, which is above the discrete interval of 1 year. Therefore, this cycle was also removed to estimate Markovian transition probability matrix (TPM). The bridge network has 306 bridges, being 292 located in Minas Gerais State and 104 in São Paulo State. Only $\mathrm{RC}$ bridges whose span is over 10 meters were considered in this approach. After the filtering, 293 bridges were left for stochastic simulation. Thus, there are seven IC for each analyzed bridge, making longitudinal the data nature.

After inspection report review, special filters needed to be developed. Inspectors diverged at components of bridge regions: for some inspectors, abutment was considered as part of mesostructure and for others, as part of the infrastructure. Similarly, some inspectors disagreed over columns regions. To reliable simulation results, these data were adequate to Brazilian standards. Besides, due to small dataset, the TPM was calculated according to the frequency approach method [13, 11, 29]. This method considers all the transition periods at one time, that is, it directly obtains the TPM pij ratios using the following expression:

$p_{i j}=\frac{N i i}{N i}$

Where $\mathrm{Nii}$ is the number of bridges in state $i$ before and after any transaction period and $\mathrm{N} i$ is the total number of bridges started with state $i$ at each transition period. Table 2 shows general IC distribution for 293 bridges on Rodovia Fernão Dias. The resulting IC distribution differs from DNIT inventory IC distribution, probably due to the current maintenance program carried out by Rodovia Fernão Dias administration. Notably, there are more bridges classified in $\mathrm{IC}=4$.

Routines were implemented to estimate TPM, using the statistical programming language " $R$ ". As explained in this methodological application, variable "age" was substituted by "inspection time", considering 2008 as starting point. Infrastructure data were not sufficient to estimate transition probabilities because there were not enough IC variations, having almost all inspections attributed $\mathrm{IC}=5$ to this region along the period. Moreover, a reduced $4 \times 4$ TPM was obtained because there was not $I C=1$ incidence. The TPM is represented by:

$\left[\begin{array}{cccc}1 & 0 & 0 & 0 \\ 0,0035 & 0,9665 & 0 & 0 \\ 0 & 0,0648 & 0,9352 & 0 \\ 0 & 0 & 0,5 & 0,5\end{array}\right]$




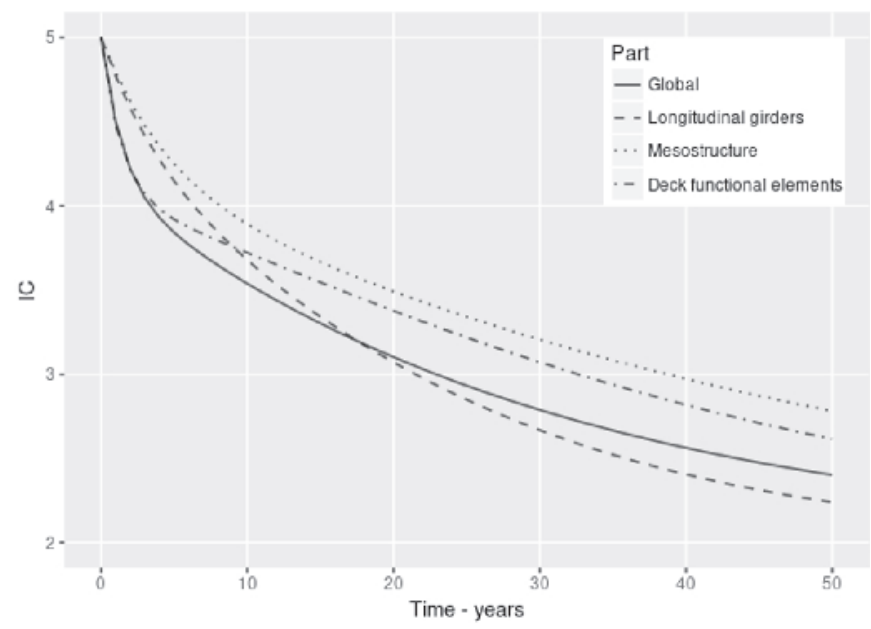

Figure 17

Deterioration model of Fernão Dias Road bridges IC per bridge region

Singular TPM was constructed for each bridge region. Deterioration rates curves are shown in Figures 16 and 17 for a 50 years period. It is possible to verify different rates for each bridge region, following the founded pattern in the Brazilian inventory. To measure methodology accuracy, singular TPM was calculated considering only the data of the first five inspection cycles (2009 to 2014) and predicted IC values for 2015 were obtained through the following expression:

$E\left(N_{t}\right)=N_{0} \cdot(T P M)^{t}$

Where, $N_{t}$ is the vector of number of bridges in each IC at interval time t. $\mathrm{N}_{0}$ is a vector of the number of bridges in each IC in a given year. Equation 5 gives the expected number of bridges in each IC after $t$ years from the initial period. It can be interpreted as expected bridge conditions preview in a specific year, with no MR\&R actions in a presumed period. Table 3 shows values of the dataset and predictive IC using the proposed methodology. The results obtained from statistical simulation are satisfactory predictors for the following year's bridge condition states of this set and have a practical use to estimate expected costs.

\section{Conclusions}

The present paper describes the current state of the bridge management procedures, as well as tools developed and implemented by DNIT. The SGO bridge management system provides a relevant inventory of catalogued road bridge structures. The overall condition of inspected bridges is presented and classified in a comprehensive way. The knowledge and availability of these results are essential for the scientific community. The data provided is vital to support current research projects and encourage others works. The appropriate use and analysis of public and official data may contribute to a more effective asset management in this area.

The inventory of Brazilian bridge conditions was evaluated by comparing IC value distribution with the presence of deterioration agents. Possible correlations were found in available data, mainly related to climate region, localization and design classification. It was demonstrated that the development of a predictive model of the future condition state for Brazilian bridges based on the age of these structures could hardly be implemented, due to the lack of registered information concerning the bridge construction time and MR\&R actions in SGO's database. However, future MR\&R action planning depends on the knowledge of future bridge condition. For instance, the article proposed a methodology using successful Markov chains for short-term predictions, considering mainly the time of deterioration from the registered condition of the bridges' first inspection. It is relevant to attempt to regular interval inspections required to Markov Chains, but if it were a challenge, the application of methods of backward prediction models could be implemented [7]. To demonstrate its applicability, the methodology was applied using Fernão Dias road bridge dataset. Results using five cycles of IC transitions were able to provide a satisfactory prediction of bridge future conditions to a dataset.

The new version of Brazilian inspection standards may cause a favorable scenario to the development of this research area. The possible use of a guided BMS by standardizes procedures on the same basis to catalogue inspection data, both for private and public bridge managers, can promote a more integrated national database, necessary to more effective management. Analyzes such as those performed on bridges of Fernão Dias road presented in this paper are difficult to be carried out due to to the lack of data in a suitable system. Furthermore, statistical simulations to forecast deterioration at large bridge network require a meaningful size for sample space. Despite the challenge of compiled disperse existing data, researches sharing this goal are being carried out to record existing inspections and estimate specific bridge deterioration rates.

To forecast more reliable deterioration rates that enable mid-term predictions, potential deterioration agents must be recorded in SGO and must be included in the inspection routine. The current traffic must be verified and updated at each inspection. It is important to precisely classify all aggressive environment aspects to enable more specific studies of diverse deterioration rates. In addition, it is necessary to improve SGO with entries of MR\&R actions to be appropriately registered. Above all, inspections procedures must result in organized and standardized information.

With this approach, it is expected in mid-term run to be feasible to determine deteriorating rates according to age, environmental conditions, traffic volume, among other possible incidences of deteriorating agents, and to measure different impacts of each agent on deterioration rates. In long-term run, adopting optimized planning of needed MR\&R actions, the Brazilian Federal Government will be able to guaranty economic development, maximizing the cost-benefit of these investments to society.

\section{Table 3}

Number of Bridges Predicted by IC using proposal methodology

\begin{tabular}{ccccc} 
& IC=2 & IC=3 & IC=4 & IC=5 \\
\hline 2014 (real) & 0 & 29 & 237 & 13 \\
2015 (real) & 1 & 38 & 232 & 8 \\
2015 (predicted) & 1 & 43 & 228 & 7 \\
\hline
\end{tabular}




\section{Acknowledgments}

The authors would like to acknowledge the support and data provided by the Federal Brazilian Department of Transportation (DNIT) and Brazilian Agency of Land Transport (ANTT). The contents discussed herein are solely based on the scientific observations made by the authors, by using publicly available data sources provided by DNIT and ANTT. For financial support, the authors would also like to thank the Brazilian Research Funding Agencies CNPq (Conselho Nacional de Desenvolvimento Científico e Tecnológico) and FAPEMIG (Fundação de Amparo à Pesquisa do Estado de Minas Gerais).

\section{Referências bibliográficas}

[1] CAVALLINE, T. L.; WHELAN, M. J., TEMPEST, B. Q., GOYAL, R.; RAMSEY, J. D. Determination of Bridge Deterioration Models and Bridge User Costs for the NCDOT Bridge Management System. Department of Civil and Environmental Engineering University of North Carolina at Charlotte, NCDOT Project, 2014-07, FHWA/NC/2014-07, 201, 188 p.

[2] MORCOUS, G. Performance prediction of Bridge Deck Systems Using Markov Chains. Journal of Performance of Constructed Facilities, v. 20 (2), 146-155, 2006.

[3] MORCOUS, G., LOUNIS, Z., MIRZA, M.S. Life-cycle assessment of highway bridges. Institute for Research in construction IRC, National Research Council Canada, 2002, 23 p.

[4] AMERICAN ASSOCIATION OF STATE HIGHWAY AND TRANSPORTATION OFFCIALS - AASHTO. The Manual for Bridge Evaluation. Washington, USA, 2013, 588p.

[5] CRUZ, C.O., MARQUES, R. C.; FRANCO, D. Road-Network Development in Quickly Growing Economies: Brazilian Case Study MG-050 Journal of Infrastructure Systems, v. 21 (4), 254-261, 2015.

[6] FONTES, F.F.; VERLY, R. C.; SANTOS, G. S.; MAGALHÃES, E. P. A Bridge Management System for Brazil. 7th International Conference on Bridge Maintenance, Safety and Management - IABMAS, Shangai, China, 2008, p. $537-543$.

[7] BU, G.P., SON, J.B., LEE, J.H., GUAN, H. Typical deterministic and stochastic bridge deterioration modeling incorporating backward prediction model. Civil Structures Health Monitoring Journal. Vol. 3, 141-152, 2013.

[8] MISHALANI, R. G., MADANAT, S. M. Computation of Infrastructure Transition Probabilities Using Stochastic Duration Models. Journal of Infrastructure Systems, vol. 8 (4), p. 139 - 148.

[9] ASSOCIAÇÃO BRASILEIRA DE NORMAS TÉCNICAS ABNT. NBR 9542: Concrete bridge Inspection. Vistoria de Pontes e Viadutos de Concreto. Rio de Janeiro, 2016.

[10] BRAZILIAN FEDERAL DEPARTAMENT OF TRANSPORT INFRASTRUCTURE (Departamento Nacional de Infraestrutura em Transportes - DNIT). Standard DNIT 010/2004 - PRO - Reinforced and prestressed concrete bridges inspections. Brazilian Road Research Institute - (Instituto de Pesquisas Rodoviárias- IPR), Rio de Janeiro, 2004.

[11] SETUNGE, S.; HASAN, M.S. Concrete Bridge Deterioration Prediciton using Markov Chain Approach. RMIT University, Melbourne, Austrália, 2011.
[12] YIANNU, P. C., NEVES, L. C., RAMA, D., ADREWS, J.D, DEAN, R. Incorporating local environmental factors into railway bridge asset management. Engineering Structures Journal, v. 128, p. 362-373, 2016.

[13] JIANG, Y. Application and Comparison of Regression and Markov Chain Methods in Bridge Condition Prediction and System Benefit Optimization. Journal of the Transportation Research Forum, Vol. 49, No. 2, pp. 91-110, 2010.

[14] PELLIZER, G.P.; LEONEL, E.D.; NOGUEIRA, C.G. Influence of reinforcement's corrosion into hyperstatic reinforced concrete beams: a probabilistic failure scenarios analysis. IBRACON Structures and Materials Journal v. 8, 479-490, 2012.

[15] NATIONAL TRANSPORT CONFEDERATION (CNT) - Survey of brazilian highways - Management Report. Brazília, Brasil, 2016.

[16] NATIONAL ROAD RESEARCH INSTITUTE - Instituto de Pesquisas Rodoviárias (IPR). Manual of road bridge inspections. Rio de Janeiro, Brazil, 2004.

[17] MARKOW, M. J.; HYMAN, W. A. Bridge Management Systems for Transportation Agency Decision. National Cooperative Highway Research Program. Transportation Research Board, Washington, USA, 2009, 127p.

[18] ASSOCIAÇÃO BRASILEIRA DE NORMAS TÉCNICAS ABNT. NBR 7188: Live Load and Pedestrian-Load in bridges, footbridges and other structures. Rio de Janeiro, 2013.

[19] ROSSIGALI, C.E., PFEIL, M. S., BATTISTA, R.C., SAGRILO, L.V. Towards actual brazilian traffic load models for short span highway bridges. IBRACON Structures and materials journal, v. 8, 124-139, 2015.

[20] WANG, H. W, LI, B., GAO, X.H., LIU, X.L. Shear behaviour of RC beams with corrosion damaged partial length. Materials and Structures, v. 45, 351-379, 2012.

[21] LIN, H, ZHAO, Y, OZ`BOLT, J., HANS-WOLF, R. The bond behavior between concrete and corroded steel bar under repeated loading. Engineering Structures, v. 140, 309-405, 2017.

[22] LENCIONI, J.W. , FERREIRA, J.B. Concrete Bridge deterioration index proposal. $56^{\circ}$ Brazilian Concrete Conference, $p$. 1-11, 2014.

[23] KENDALL, M. G. GIBBONS, J. D. Rank correlation methods. Oxford University Press, New York, NY,1990.

[24] MOSCOSO, Y. F. M. Deterioration models to Bridge Management Systems. Doctoral Thesis. Brazilia University (UNB), 2017.

[25] BOLUKBASIL, M., MOHAMMADI,J. ARDITI, D. Estimating the Future Condition of Highway Bridge Components Using National Bridge Inventory Data. Practice periodical on structural design and construction. American Society of Civil Engineers, v.1, 16-25, 2004.

[26] THOMPSON, P. Decision Support Analysis in Ontario's New Bridge Management System - Proceedings of the 2001 Structural Congress and Exposition. ASCE,Washington, D.C, 2001.

[27] NASRROLLI MASSOUD, M., WASHER, G. Estimating Inspection Intervals for bridges based on statistical analysis of national bridge inventory data. Journal of Bridge Engineering, vol. 20 (9), 2015. 
[28] AGRAWAL, AK \& KAWAGUCHI, A., Bridge element deterioration rates: final report, project C-01-51. New York State Department of Transportation, New York, NY, USA. p. 15 a 21, 2009.

[29] MUÑOZ, Y. F., PAZ, A, FUENTE-MELLA, H., FARIÑA, J. V., SALES, G. M. Estimating Bridge Deterioration by Using Small Data Sets. University of Nevada, USA, 2016. 